\title{
Comparing effects of reward size and action contingency on single neurons of monkey medial vs. lateral orbitofrontal cortex Barry J Richmond* and Sebastien Bouret
}

\author{
Address: Laboratory of Neuropsychology, NIMH/NIH/DHHS, Bethesda, MD 20892 USA \\ Email: Barry J Richmond* - bjr@In.nimh.nih.gov \\ * Corresponding author
}

from Eighteenth Annual Computational Neuroscience Meeting: CNS*2009

Berlin, Germany. 18-23 July 2009

Published: 13 July 2009

BMC Neuroscience 2009, I0(SuppI I):PI5 doi:I0.I I86/I47I-2202-I0-SI-PI5

This abstract is available from: http://www.biomedcentral.com/I47I-2202/I0/SI/PI5

(c) 2009 Richmond and Bouret; licensee BioMed Central Ltd.

\section{Introduction}

The orbitofrontal cortex, based on connectional anatomy, has been divided into more lateral (OFC, areas 11/13) and medial areas (VMPFC, i.e., ventromedial prefrontal cortex, areas 14/25/32). Although these areas are often assigned two different subnetworks for processing emotion and reward, they are both thought to be important for assessing values of stimuli predicting outcomes. We used two related types of behavioral trials to the effect of compare the effects of stimulus-outcome and stimulusaction-outcome contingencies on the information encoded within populations of single neurons in these brain regions.

\section{Methods}

Each trial begins with a visual cue that informs the monkey about both the trial type, operant or passive, and the amount of reward to be delivered at the end of the trial. In the operant trials, the monkey had to release a bar when a red fixation point turned green to obtain the reward. After correct bar release, the green spot point turned blue (feedback signal). In the passive trials, after the cue appeared, nothing else happened until the blue point appeared on the screen just before reward delivery. Behavioral sensitivity to the cues was assessed by measuring operant (reaction times and error rates) and Pavlovian (lipping) responses. In operant trials, reaction times and error rates were higher in low-reward trials, showing that the monkey was sensitive to the cues. We also measured lipping, a Pavlovian response to cues and feedback. We recorded single neurons in both areas (one at a time) while the monkeys carried out this task.

\section{Results}

Cue-evoked lipping was linearly proportional to the reward size in both operant and passive trials, indicating that cues were associated with predicted outcome. In the operant trials, the error rates and reaction times were inversely related to the reward size: the measured values became smaller as the rewards became larger. Thus the Pavlovian responses indicate that our monkeys extract information about reward size and presumably they adjust their operant responses in active trials using that cue-related information. We recorded 105 OFC neurons and 107 VMPFC single neurons. Both regions showed responses that were sensitive to reward and to whether the trial was operant or not. These responses occurred in relation to the cue, a green or red spot, the predictive signals, in relation to the go and feedback signals, and upon reward delivery itself. The proportion of neurons sensitive to reward size was larger in OFC than in VMPC, whereas the number that were sensitive to whether or not the trial was operant was the same. Sliding window (300 ms wide, steps $20 \mathrm{~ms}$ ) 2-way ANOVAs for reward size and action contingency around cue onset and feedback signal for each neuron showed that encoding for reward accounted for much more variance and appeared systematically earlier in OFC than in VMPFC. The signal for the action contingency became conspicuously larger for about $300 \mathrm{~ms}$ at the time of the feedback signal in VMPC. 2-way ANOVAs 
also revealed that just after the cue about $25 \%$ of OFC neurons and $15 \%$ of VMPFC neurons are sensitive to reward size only and another $15 \%$ in both areas are sensitive only to whether or not the trial is operant or not. There are a few neurons that carry linearly combined signals (both main effects in ANOVA) and a few that are showing a one main effect (or the other) with significant interaction.

\section{Conclusion}

In line with current ideas about information processing in OFC and VMPFC, both brain areas contain neurons that are sensitive to reward size, the reward value in these experiments. In line with recent work, the representation of this signal is especially strong in OFC. It is perhaps not surprising that both areas have neurons that are sensitive to the distinction between the need for an action or not. Perhaps unexpectedly, there are subpopulations of neurons in both regions that only code for information about reward value and others that only code for the need for action. The number of neurons combining signals is not a coherent group. These resultsis raises questions about how these seemingly segregated signals arise, and what the targets might be.
Publish with Biomed Central and every scientist can read your work free of charge

"BioMed Central will be the most significant development for disseminating the results of biomedical research in our lifetime. " Sir Paul Nurse, Cancer Research UK

Your research papers will be:

- available free of charge to the entire biomedical community

- peer reviewed and published immediately upon acceptance

- cited in PubMed and archived on PubMed Central

- yours - you keep the copyright

Submit your manuscript here:

http://www.biomedcentral.com/info/publishing_adv.asp 